\title{
REVIEW
}

\section{Mika Ojakangas. A Philosophy of Concrete Life. Carl Schmitt and the Political Thought of Late Modernity.}

\section{Stefan Fietz}

During the last years, the thought of Carl Schmitt has regained wide international attention. His ideas on "The Concept of the Political", on "The Crises of Parliamentary Democracy" or on "The Nomos of the Earth" are now highly regarded as important contributions to discussions on several topics in the field of political theory. To read Carl Schmitt, many of today's left-wing political theorists claim, will help us to rethink democracy, to show up its internal paradoxes, ${ }^{1}$ to point at its "dark sides". ${ }^{2}$ According to their readings, it will also provide us with a better theoretical understanding of war and other phenomena of violence in politics. And, last but not least, Carl Schmitt is viewed to help us developing a new understanding of political theory, which takes seriously the specific internal agonal logic of "the political" and does not mix political with ethical thought. In short: Carl Schmitt is presented as a theorist who helps us rediscovering politics in its purity.

I.

Taking these debates into account Mika Ojakangas' study A Philosophy of Concrete Life. Carl Schmitt and the Political Thought of Late Modernity is a very important one. The book has two aims. At first, Ojakangas 
offers a very rich and informative introduction into Carl Schmitt's thought as a whole. All of Carl Schmitt's central texts and concepts are precisely interpreted. His thought is not so much presented in a chronological, but more in a systematic way. Thus Ojakangas tries to show, that Schmitt's work is tied together by one single question: what are the concrete preconditions of order? This is the first and maybe the central thesis of the book: Ojakangas claims, that Carl Schmitt is a highly systematic and philosophical author. He thus contradicts other interpretations of Schmitt's work, which emphasise the unsystematic character of his thought. ${ }^{3}$

Ojakangas' second aim is not so obvious at the first sight. But I think, with his specific interpretation, he also aims at contradicting some assumptions, which have been put forward in the current discussions of Schmitt's work.

In what follows, I first want to reconstruct Ojakangas' central ideas (II.). Due to limited space I can only present the central lines of Ojakangas' argumentation. Then, I want to present shortly some conclusions, what Ojakangas' interpretation would mean for the current debate of Schmitt's thought (III.).

\section{II.}

Starting to read the book, one immediately gets the impression, that Ojakangas wants to read Schmitt like many of his current commentators. Ojakangas starts with some very short critical comments on the liberal theory of John Rawls and, as another type of current political thought, on Communitarianism, accusing them both for having forgotten "the concrete essence of politics" (p. 10). For Ojakangas, Carl Schmitt is the "most promising" (p. 10) author for developing a political theory, which takes "the political" seriously and thus turns away from ethical theories of politics formulated by liberals and communitarians as well. There are other hints in this book, which seems to indicate that Ojakangas wants to read Schmitt as a contributor to current discussion on developing a "political political theory". Ojakangas wants "to actualise" (p. 11) Schmitt's thought. Out of this reason, he puts him in a context with authors like Hannah Arendt, Michel Foucault, Ulrich Beck and Gilles Deleuze, who are in favour of pluralism (Beck), who are suspicious concerning modern ethics and an ethical political theory (Foucault and Deleuze) and who are searching for a genuine concept of the political (Hannah Arendt). 
But while continuing reading, one gets aware, that Ojakangas is not so much interested in an autonomous theory of "the political". For him, Schmitt's concept of the political must be seen in its close connection with his search for the concrete preconditions of order. Schmitt was of the opinion, that in modernity this question was totally neglected. So he thought it to be his task to inveigh against the modern worldview and to point out its shortcomings.

For this interpretation, Ojakangas applies Schmitt's method of the "sociology of concepts" to Schmitt's thought. Ojakangas is of the opinion, that all of Schmitt's central concepts like "sovereignty", "decision", "the political" or "land-appropriation" (pp. 151/152) are on the one hand "counter-concepts" against what Schmitt himself identified as the "metaphysical image" (p. 11) of modernity. On the other hand, all his concepts function as a kind of "ground concept", formulating the preconditions of order (p. 26). Carl Schmitt thus tries to analyse what lies at the heart of our modern political order and what is its ultimate and thus extreme precondition for coming into existence. Speaking metaphorically, Schmitt always tries to think on the extreme border of order (p. 26).

What is the metaphysical image of modernity, which has lead to a negligence of questions for preconditions of order? In the eyes of Schmitt, modernity is characterised by rationality, by technology and by absolute immanence. It seems, that the modern world runs automatically like a "self-propelling machine" (p. 24/25). Schmitt finds this kind of worldview especially expressed in the thought of Hans Kelsen, who searches for a science of law founded on a transcendental, highly abstract "basic norm" (p. 37). But the radical immanence of modern life also finds its expression in the practice of modern liberal democracy and its core institution, the parliament with its infinite debates and discussions (pp. 90/91). The problem of liberalism lies thus in the fact, that it is not aware of the concrete political institutions or actions, which alone are able to safe an political order's existence. In this sense, liberalism does not reflect and acknowledge its own preconditions. It does not transcendent itself.

Schmitt introduces several concepts in order to polemicize against this immanent worldview while searching for an even more concrete precondition of order. The first one is the concept of the sovereign, which is directed against Kelsen's "basic norm". For Schmitt, only the concrete instance or person of the sovereign can be the basis of a juridical or political order. (p. 39). The sovereign does not stand outside 
the order, but is placed on its very border and is thus the core and the precondition for order or disorder.

But in his search for concreteness, Schmitt goes even further. The concept of the sovereign is concretised in the concept of "decision": "Schmitt holds that every order rests thus on a decision: 'It is the decision that grounds both the norm and the order.' The decision (Entscheidung) is the 'absolute beginning', the 'first cause' and the 'ultimate origin', the arkhe of any political entity." (p. 40). And at the heart of "decision" lies the concept of the political with its precondition of identifying an enemy (p. 65). In Ojakangas' interpretation, Carl Schmitt's work seems to be motivated by the desire of finding and conceptualising an even more concrete condition of political order. Carl Schmitt takes several conceptual steps from "sovereignty" to "the political", in which every new conceptual step tries to concretise the former conceptual step. In this way every step brings us closer to the ultimate border, to the most extreme origin of order.

But what about the later work of Carl Schmitt, where the concept of the political does not stand in the centre anymore, but is replaced by the concept of "nomos"? Has the later Schmitt given up his search for concrete origins of order?

Ojakangas is of the opinion, that Schmitt's turn to the concept of "nomos" was again motivated by his search for concreteness. "In 1934 he [Carl Schmitt, SF] merely reached the conclusion that reflection which overemphasises the act of decision does not fulfil the precondition of concreteness in the philosophy of concrete life but, on the contrary, floats like the normativist norm, 'freely in the air'." (p. 115) Schmitt's theoretical turn is motivated by the self-critical insight, that his concept of decision and of the political was not concrete enough. In the end, it rather had at least some similarities with Kelsen's transcendental basic norm. A reformulation of Schmitt's theoretical project is necessary. The concrete condition of order must now be found in something different then in the decision and in the political. For Schmitt the nomos as "the totality of the conditions prevailing in a political, social and religious order" (p. 116) is the new term to conceptualise "the concrete". At the heart of the nomos lies the first act of land-appropriation (p. 117), which makes the division of land between men necessary, being thus the precondition of formulating a judgement (Ur-teil) (p. 119) and the development of laws (p. 118/119) on the one hand. On the other hand, the act of dividing land establishes a "concrete spatial order" (p. 117), which leads to a "localisation" (Ortung). According to Ojakangas, "localisation" (Ortung) also 
implies "the possibility of orientation in the world" (p. 118). In other words it implies the possibility of developing moral norms, which define a kind of "standpoint" in the world and attitudes towards the world and other people.

Compared to his "decisionist" and "political" phase, however, Schmitt has obviously changed his idea of concreteness as a precondition of order. It does not so much rest on a rupture (p. 25) or on an event (p. 45) anymore. In the later work of Schmitt, concreteness finds its expression in "the concrete institutional order and its historical development." (p. 115). But is the concrete nomos anything different from the concrete moral and juridical tradition of a certain community then?

\section{III.}

I do not want to discuss whether Ojakangas' interpretation of Schmitt's texts is always correct. I sometimes have some doubts, especially concerning his interpretation of nomos and other topics of Schmitt's later work. As far as I know, the later Schmitt is more engaged in analysing problems of war and politics. Ojakangas himself writes a little bit on these questions in his chapter on "The Nomos of the Earth" (pp. 127-134), but it is not always clear, what his explanations have to do with the topic of "concreteness" then.

In what follows, I would like to discuss what consequences Ojakangas' interpretation might have for the current left-wing discussions of Schmitt's thought. From my point of view, Ojakangas has written a very interesting and lucid criticism of this reception of Schmitt's thought which is best represented in the book The Challenge of Carl Schmitt edited by Chantal Mouffe in 1999. As mentioned above, this approach is characterised by the attempt to redefine the political and to conceptualise it with the help of Carl Schmitt. Ojakangas obviously takes his starting point from these discussions. But while following Schmitt's thought he gets aware, that Schmitt himself saw some difficulties in his own concept of the political. According to Ojakangas, Schmitt tried to overcome this problem by pointing at aspects like morality (implied in the concept Ortung) and its historical development. In other words: Schmitt pointed at aspects of political tradition and culture.

The reason for this development was, following Ojakangas, that "the political" was just not representable in a political order. For 
Schmitt himself, it floated freely in the air." (p. 115). According to Ojakangas, there were only two ways of making "the political" in its borderline existence on the edge of order present and concrete in political and juridical processes. The first possibility of representing "the political" were states of exception (Ausnahmezustand), war or killing: "Real killing reveals the concrete core of the political." (p. 71) However, following Ojakangas analyses, "killing itself [...] cannot be included in the sphere of the political. Killing at war is merely the ultimate borderline of politics, the extreme case. Just like the state of exception, war is a borderline concept [...]" (p. 71). That means that for Schmitt the attempt to represent "the political" through states of exception and war failed. It did not make "the political" in any case more concrete or visible. It did not make "the political" a factor in social life itself. The other possibility, which Ojakangas discusses, is a kind of symbolic representation of the "political" in its borderline existence, where "the political" gets present in dramas on theatre, in tragedies (pp. 72-77), in social myths (pp. 103-108) or in specific institutions (pp. 103-108). But trying to represent "the political" symbolically in social myths means nothing else then making it present in cultural memory and tradition. The consequences of this interpretation would be, that the later Schmitt either got aware that "the political" can only be a kind of social construct, which might exist in the cultural imagination of certain communities, but is not a concrete form of action. Or he came to the opinion, that "the political" as a concrete form of action needed to be integrated in the political culture and tradition, in the nomos of a certain community.

But if this interpretation is correct, then all the current attempts of introducing Carl Schmitt as someone, who brings "the political" in its purity back into political theory, would be at least questionable. On the one hand, Carl Schmitt tries to conceptualise "the political". But on the other hand he sees the problems of conceptualising (p. 152) and representing it and argues for an ethical or pre-political basis for "the political" or at least for a kind of mythological representation of it in the cultural memory of a society. Maybe, Carl Schmitt was even one step ahead of some of his current interpreters. In her introduction of the book on Carl Schmitt edited in 1999, Chantal Mouffe writes, that Schmitt's theory of the political and political antagonism would need an addition, namely the idea of a "common symbolic ground" existing between political rivals. In Ojakangas' interpretation, the later Carl Schmitt has not only seen this need for a "symbolic ground", he had already formulated some ideas, wherein this "symbolic ground" 
could lie, while current interpreters of Schmitt's thought leave this idea quite open and just claim its necessity.

The reader of Ojakangas' study can thus learn that Carl Schmitt might be the wrong source of inspiration for all those left-wing theorists in search for a "theory of the political". On the one hand, Schmitt did not see "the political" as something autonomous. He always conceptualised it together with the idea of order (p. 108). Carl Schmitt is more a philosopher of order than of "the political" according to Ojakangas. On the other hand, Schmitt himself became critical towards "the political". This is not to say that a theory of "the political" is impossible. This is only to say that Carl Schmitt himself would certainly have criticised current attempts to formulate such a theory and that he would have felt himself misunderstood by some of his current interpreters. This, of course, does not make Carl Schmitt's thought any better. It only shows once more, that Carl Schmitt is a heavily right-wing theorist - and that one should leave him in this corner, analysing his thought as critically as possible and avoid attempts of a new left-wing reception.

\section{NOTES}

1. Mouffe, Chantal: Carl Schmitt and the Paradox of Liberal Democracy. In: Mouffe, Chantal (Ed.): The Challenge of Carl Schmitt. London/New York: Verso 1999, pp. 38-53

2. Agamben, Giorgio: Homo Sacer. Die souveräne Macht und das nackte Leben. Frankfurt/ Main: Suhrkamp 2002

3. For example, Reinhart Mehring presents Schmitt as an unsystematic thinker. See: Mehring, Reinhart: Carl Schmitt zur Einführung. Hamburg: Junius 2001, p. 7.

4. Mouffe, Chantal: Introduction: Schmitt's Challenge. In: Mouffe, Chantal (Ed.): The Challenge of Carl Schmitt. London/New York: Verso 1999, pp. 1-6, here: p. 5 